\title{
International Sharing of the Remote Laboratory NetLab
}

\author{
https://doi.org/10.3991/ijoe.v16i11.16601 \\ Andrew Nafalski $(\bowtie)$ \\ University of South Australia, Adelaide, Australia \\ andrew.nafalski@unisa.edu.au \\ Marek Miłosz \\ Lublin University of Technology, Lublin, Poland \\ Hugh Considine \\ University of South Australia, Adelaide, Australia
}

\begin{abstract}
In this paper we report on the use of the NetLab remote laboratory located in Australia, accessed outside the country, including Sri Lanka, Poland, Singapore and Sweden and other tens of locations. After a review of the current use and the development of NetLab, we concentrate on the overseas applications of the remote laboratory. There is an increasing recognition by students using remote laboratories that their learning experience is comparable with working in real laboratories. Remote laboratories enable working in a safe, an international, multicultural environment, becoming more and more important in the era of globalisation and coronavirus.
\end{abstract}

Keywords - NetLab, Remote Laboratories, Sharing Remote Laboratories, Flexibility, Learning Outcomes, Online Access.

\section{$1 \quad$ Introduction}

The online delivery of subjects, courses and even complete degrees is growing exponentially in educational institutions [1]. To prepare academics for online teaching, a number of programmes such as Learning to Teach Online (LTTO) [2] at the University of New South Wales, Sydney, Australia are available internationally, as Massive Open Online Courses (MOOCs). The course is offered through the organisation Coursera that delivers materials $100 \%$ online, with some 3,600 courses, 2,390 specialisations, 15 certificates and over 14 degrees in collaboration with top universities and companies worldwide. Since 2012, some 40 million learners have enrolled in the Coursera's offerings [3].

Laboratory work is an indispensable part of courses in engineering and science to provide hands-on experience with laboratory equipment and to develop high level technical, communication and collaboration skills, supported by relevant underlying theories. Existing laboratories can be classified as real (proximal), virtual and remote, or combination of them. Each type of laboratories has its merits and limitations and should be applied as complementing rather than replacing each other. 
After reviewing remote laboratories (RL) in general, we focus on the use of the remote laboratory NetLab by users from overseas. These include coursework components of the University of South Australia subjects offered offshore as well as subjects supplied by overseas universities with the application of the remote laboratory in Australia. Student perceptions of the remote laboratory and teaching online, changing over time, are reported.

\section{Remote Laboratories and its Effectiveness in Education}

There is a growing consensus that remote laboratories offer a learning experience similar to real laboratories. RLs operate on real equipment and have components controlled via the Internet from anywhere in the world. They are also cost effective, as usually only one set of equipment is sufficient for the class, are available 24/7, and do not require costly scheduling and supervision. Research conducted among students indicates that learning outcomes obtained by them in the process of education using hands-on and remote laboratories are very similar [4].

These studies used Standard Aptitude Test (SAT) scores, and Grade Point Average (GPA) analysis. In order to assess student satisfaction with the remote labs work was assessed by a questionnaire (the Student Feedback Form - SFF) constructed for that purpose. The overall satisfaction of using the remote laboratory in the study rating [4] achieved an average of 7.15 (out of 10) and convenience of scheduling - 8.44. Convenience in access was rated at 8.56.

These studies confirm the thesis about the high efficiency of remote laboratories in the student education process. Other studies [5] confirm the high valuable content of remote laboratories in students' survey results. Students were asked to rate as a number from 1 (least troublesome) to 7 (most trouble) how access to laboratory equipment was a problem. For those using remote laboratories, the availability difficulty was 1.7. For those in hands-on labs, the rating was 4.6, indicating that access to hands-on labs is more difficult [5].

This means that remote laboratories are more (many times: 3-4 times) available for students than hands-on ones. Other studies indicate [6] that remote laboratories primarily develop educational goals: conceptual understanding and professional skills, but do not develop design skills. Remote laboratories allow students to perform experiments in many different areas of engineering and science, including mechanical, control, electrical, computer and electronic engineering, computer science and physics.

Remote laboratories can use different contemporary technologies, for example Augmented Reality [7], WebSockets, Java / JavaScript and Smart Device Specification (SDS) [8, 9], OpenSim, VirtualWorlds and Unity3D technology [10].

The remote laboratories also, in a collaborative environment, like NetLab, offer an interface similar to that of interactive social media, which is familiar to the majority of students [11]. The online experience with a remote laboratory, increases students' relevance to the contemporary study and work setups. 
The scope of remote laboratory environments, both by open and paid-for access (which is generally not preferable) is quite vast now. These environments support many branches of engineering, in addition to science and IT disciplines [12].

To increase the availability and capabilities of remote laboratories, universities may create consortia to build a single point of access to a group of laboratory stands. This approach significantly reduces the costs of building remote laboratories and extends the possibilities of cooperation of students from different countries in joint experiments.

There is growing evidence [13] that usage of remote laboratories has a significant positive impact on student attainment in learning.

\section{The Remote Laboratory NetLab}

NetLab is a RL developed at the University of South Australia (UniSA) and improved every year since its first use in 2002 in teaching of a number of subjects including Electrical Circuit Theory, Signal and Systems, Introduction to Electrical Engineering, Electricity and Electronics. The development of NetLab involved a large number of $\mathrm{PhD}$, MEng and BEng projects. NetLab was incorporated into the practical work in courses at UniSA, both domestically and internationally in transnational programmes in Singapore and Sri Lanka. Tens of thousands of learners from some 94 countries used the NetLab over the years.

One of the aims of the remote laboratory NetLab is to enhance students' flexibility of access at anytime from anywhere. NetLab also has advantages for students with disabilities, and for improving the learning experience of all students. Unlike as in real laboratories, students can repeat their experiments as many times as necessary to obtain required results, learning in the process how to effectively use the laboratory equipment.

NetLab is an interactive collaborative environment where all concurrent users have full control over all equipment. As such, it supports an effective interaction between users and the equipment as well as between the users themselves. Thus, the other aims are to not only to develop student practical skills but also cooperation and collaboration skills, as well as oral and written communication proficiency.

\subsection{Open access}

NetLab is an open access laboratory, i.e. everybody can use it after creating their own account, by registering, defining a password and booking a time slot using NetLab booking system. This allows any users from any location in the world with the Internet access to conduct experiments in NetLab. Although, technically a large number of students can use the laboratory simultaneously, for practical reasons the number of users is limited to 3 at the same time. This means users can work alone or in 2 or 3 -person teams. For research purposes the number of participating users can be increased as in [16]. 


\subsection{Technical aspects}

The NetLab Server communicates with the users through the Internet. On the other end, the server communicates with a number of programmable laboratory instruments via the IEEE 488.2 standard interface, also known as the General-Purpose Interface Bus (GPIB). These instruments include a digital oscilloscope, a function generator and a digital multimeter. All these instruments and components are connected to a 16x16 programmable matrix relay switch which allows the user to wire and configure various electrical circuits from available components and instruments shown in Figure 1.

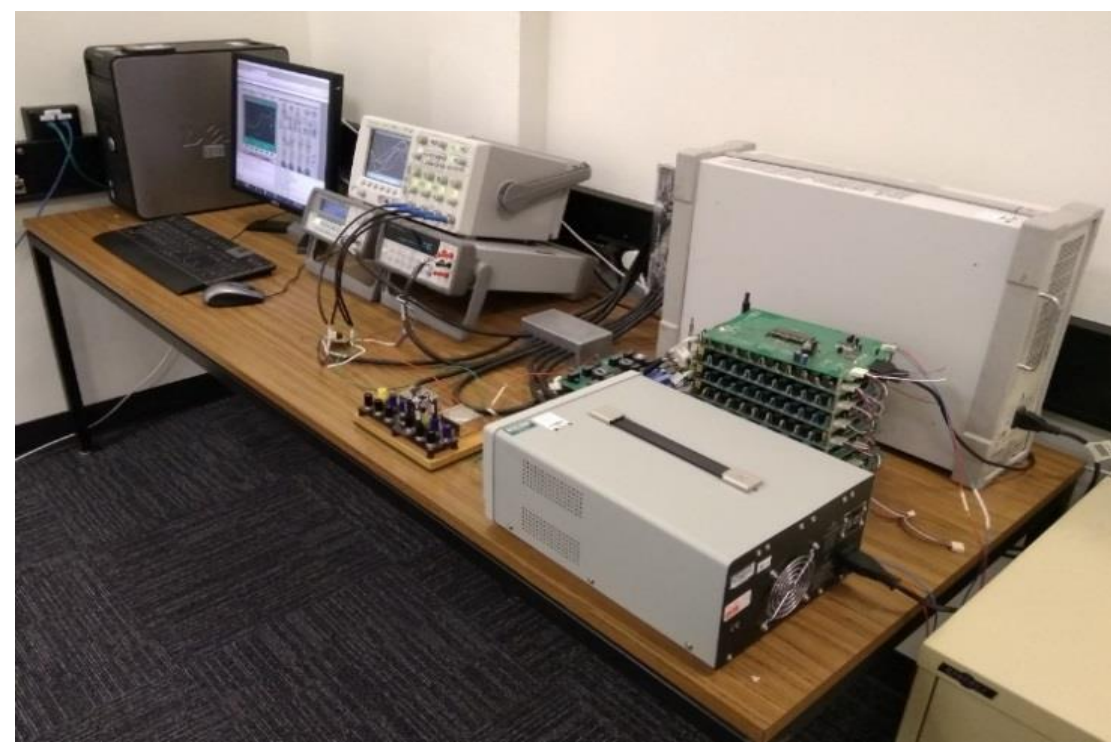

Fig. 1. Physical appearance of NetLab

The objects in Figure 1 from the left indicate the NetLab server, its screen and the instruments. On the right, at the back is the switching matrix, and in the front of it variable components (RLC plus a transformer) with their power supply in the right front.

Figure 2 shows an image of the software as presented on the user's computer. It illustrates the digital oscilloscope's animated screen with four channels active. The measured data can be saved to the user's computer for plotting and further analysis in programs such as MATLAB.

The circuit connections shown on the lower left (Figure 2) are a combination of RL, $\mathrm{RC}$ and resistive voltage divider circuits, configured in the Circuit Builder. The oscilloscope screen (which is also visible by a web camera on the user's computer) and the user's screen are matching each other.

On the lower right, there is a window showing all users' actions in the laboratory. This is an example of data which allows learning analytics techniques to have an informed action in the Intelligent Tutoring System development [14]. 


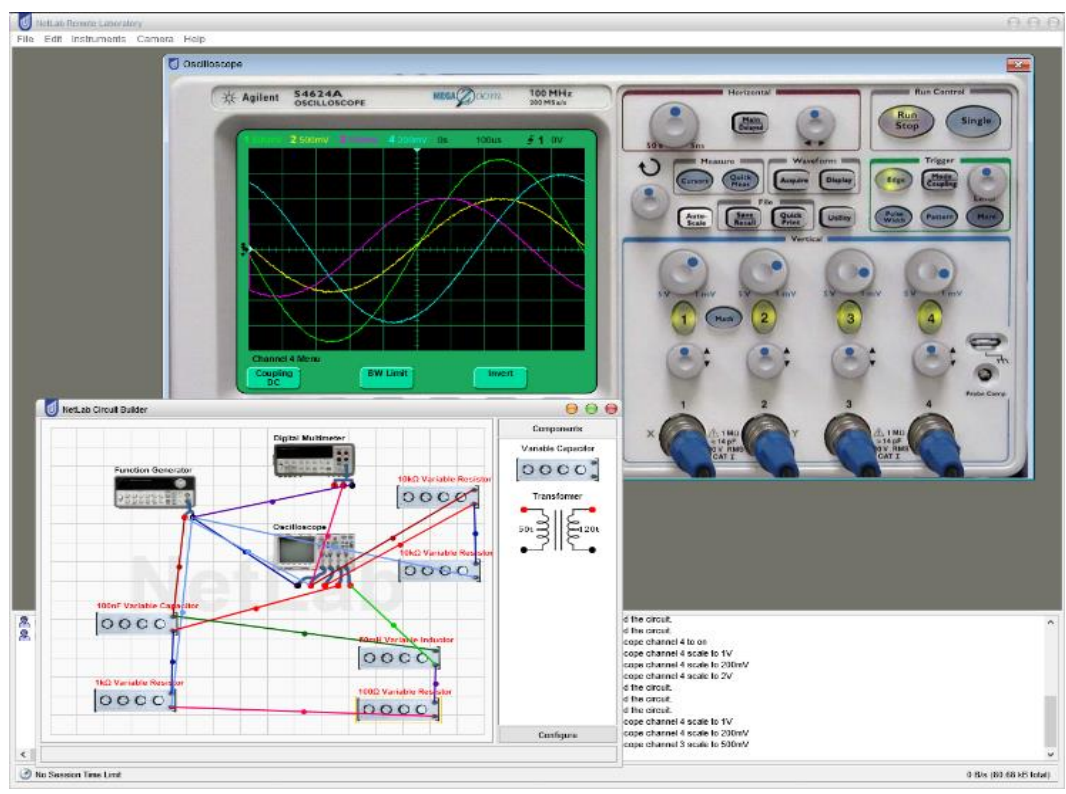

Fig. 2. An example of the NetLab's interface

\subsection{Circuit builder}

The Circuit Builder software is designed in a way to mimic circuit wiring in a real laboratory. Using the Circuit Builder's interface, available components may be dragged from the component pane into the circuit diagram. Components can then be connected using a click and drag of a mouse from the start to the end of connection nodes. After the Configure button is pressed the circuit is physically wired through the switching relay matrix.

Implementation of the Circuit Builder (Figure 2) not only enables users to perform remote wiring, but also allows them to use the laboratory for running different experiments, without the need to physically interfere with the laboratory equipment.

\subsection{Current developments}

A significant amount of work is underway on the NetLab remote laboratory, on both the hardware and software parts of the system.

A major expansion of the hardware is currently being designed. The expansion will add a larger switching matrix, which will then allow for additional components to be connected. The new matrix will be rectangular rather than the current square matrix, and the change in shape will allow a change in the routing algorithm to support polarised components. The components will include transistors, diodes, operational amplifiers and additional passive components to increase the complexity of the circuits. Also, the GPIB interface will be replaced with a USB connection. 
The software is also undergoing some significant changes. An Intelligent Tutoring System is currently under development for the remote laboratory. An initial system was evaluated in 2019, and the expanded tutoring system will be tested in 2020 .

The NetLab software is currently implemented in Java, and some changes in Java availability have caused issues. The NetLab client was launched using Java Web Start, which is no longer supported institutionally in newer versions of Java.

The institutional Java licences require now a substantial fee to be paid. As a workaround, the NetLab client will be provided using the WebSwing toolkit, which allows any HTML5 browser to access NetLab.

With these changes, NetLab will allow more students to access the system, allow them to do more experiments using it, and provide them with better support when they experience difficulties.

\subsection{The status}

The 18 years of NetLab availability brings it to the record use time of remote laboratories world-wide. It is now an open-access, robust, reliable and user-friendly remote laboratory. It has been designed to resemble the students' work in a real laboratory as closely as possible and includes provision for students' collaboration in teams as a quite unique feature in the case of remote laboratories.

Students using remote laboratories usually have a limited human assistance available due to the nature of 24/7 access. To address this, an Intelligent Tutoring System for Remote Laboratories with the Application of Learning Analytics is being developed $[14,15]$.

\section{Overseas Use of NetLab}

\subsection{International usage}

Students of transnational programmes of the University of South Australia in Singapore and Sri Lanka used NetLab in the subjects listed in Section 3.

An interesting case of using NetLab in international teams from several campuses of the University of South Australia, Singapore transnational students and Swedish students from Blekinge University of Technology - the partner in the grant [16], was accomplished.

Students collaborating internationally online may have a different discipline knowledge, resulting from their educational background and/or the level of advancement in their programmes. The experiment instruction hand-outs should include as many details as possible on the necessary or assumed discipline knowledge and should include references to relevant materials. The collaborative learning tasks must also use a form of topics and problems to initiate interaction between students.

Online technology is constantly evolving, and it is important that all participating students have proficiency in using the technology selected for communication as well as the remote laboratory itself. 
RLs offer students opportunity to collaborate with students from other countries and enrich their cultural experience (cultural intelligence) and online collaboration skills.

The first NetLab international project [16] involved four 4-person teams (2 students from the University of South Australia and 2 transnational students from Singapore in each team). They worked on an experiment of the $3^{\text {rd }}$ order circuit in the subject Signals and Systems. Session times were restricted, which meant the cultural interactions were limited, with communication becoming more of the functional nature rather than of a personal or cultural nature.

In the second project of the same grant [16] encompassed the NetLab based collaboration in a circuit theory experiment of students from Australia with students from Sweden. We included remote laboratory materials related to cultural diversity, and it was very successful. The collaborating students made friends with their partners continuing beyond the joint experiments. A lot of humour was present in the communication.

The framework for international collaboration in remote laboratories that addresses three aspects that affect these collaborations is shown in Figure 3 [17].

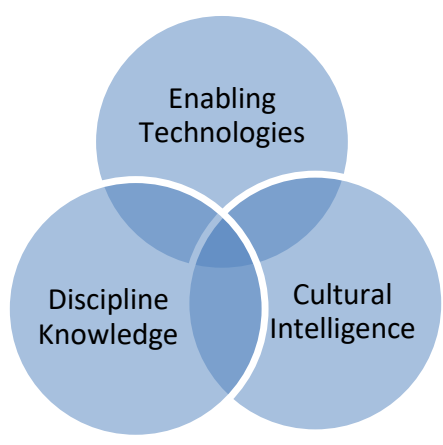

Fig. 3. Aspects affecting international online collaboration [17]

Our unique trial of laboratory experiments executed internationally shows that careful planning and preparation of the collaborating team is required to maximise the expected outcomes. This is important as international intercultural capabilities are increasingly required for geographically dispersed teams working on joint projects.

\subsection{NetLab in subjects of an overseas university}

Between 2013 and 2020, every year, academic teachers from the University of South Australia have been teaching students from the Lublin University of Technology, Poland, both in blended and purely online modes.

Over 330 students from Poland were enrolled in the subjects taught in English by Australians. The subjects included: Information Technology (IT), Monographic Lecture on Remote Laboratories, Engineering Applications of IT, Final Year Project Seminars, Modern Techniques of Teaching Delivery, Scientific-Technical English, IT Tools in Scientific Research, and Preparation of Scientific Articles and Presentations. Some 
of the subjects have been offered several times. The range of student levels varied from BEng (in Computer Science or in Electrical Engineering) through to Master of Engineering (two specialisations - Computer Science and Electrical Engineering), and $\mathrm{PhD}$ students in Electrical Engineering.

In all those subjects NetLab was used either for demonstration and explanation of the operation of remote laboratories, or an active use of the remote laboratory, or both. In the Monographic Lecture on Remote Laboratories, M.Eng. students were required to conduct an experiment using NetLab, located in Adelaide and to write practical reports in English.

\subsection{New experiments in NetLab}

In PhD subjects in Lublin, students were encouraged to develop new experiments in NetLab (including theoretical background, procedural instructions and a report template), conduct the experiments and write exemplary reports. The reports included a comparison of results of measurements on real equipment obtained by using NetLab, simulations using Multisim/OrCAD, analytical results from mathematical, and the justification of any major discrepancies.

In 2018 and 2019 in the Monographic Lecture on Remote Laboratories, Lublin PhD students together with Australian academics have developed four new NetLab experiments, in addition to existing ones [18]: Determination of Parameters of a Transformer, High Pass Filter, Thévenin's Theorem, and Parallel Resonance.

\subsection{High pass filter-the experiment definition}

The aim of the High Pass Filter (HPF) experiment is to examine the frequency and time characteristics of a simple high-pass RC filter. The findings will be verified by comparing the simulation results (from OrCAD or MATLAB) with the experimental results obtained by performing the real experiment using the remote laboratory NetLab.

HPFs are filters that stop the passage of low frequency signals and allow the passage of high frequency signals. A capacitive model of a first order high-pass RC filter is shown in Figures 4 and 5. As the frequency at the input increases, the impedance of the capacitor decreases. Hence, the capacitor allows passage of high frequency signals.

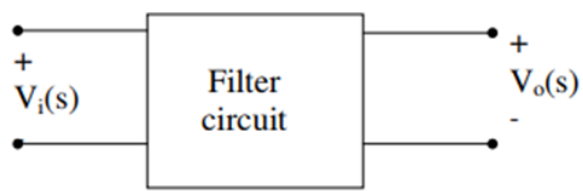

Fig. 4. Filters - linear circuits that can be represented as two-port network 


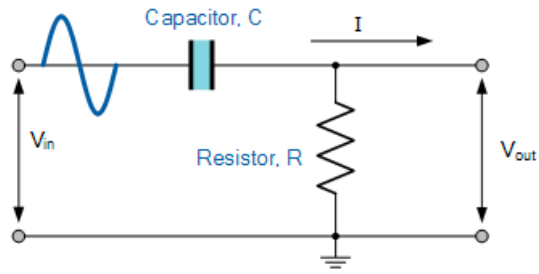

Fig. 5. A passive, first-order high-pass filter, realised by an RC circuit

High pass filter - the theoretical issues: The resulting transfer function for the circuit from Figure 5 is given by formula (1) from [19]:

$$
H(f)=\frac{V_{\text {out }}}{V_{\text {in }}}=\frac{j\left(\frac{f}{f_{B}}\right)}{1+j\left(\frac{f}{f_{B}}\right)}
$$

in which: $f$ - means frequency, and the break frequency $f_{B}$ is given by:

$$
\mathrm{f}_{\mathrm{B}}=\frac{1}{2 \pi \mathrm{RC}}
$$

While the magnitude of the transfer function is given by:

$$
|H(f)|=\frac{\frac{f}{f_{B}}}{\sqrt{1+\left(\frac{f}{f_{B}}\right)^{2}}}
$$

and the phase of the high pass transfer function is given by:

$$
\mathrm{H}(\mathrm{f})=90^{\circ}-\arctan \left(\frac{\mathrm{f}}{\mathrm{fB}}\right)
$$

The magnitude and phase for the first-order high-pass transfer function are shown in Figure 6.

Note that the transfer function magnitude goes to zero for $\mathrm{dc}(\mathrm{f}=0)$. For high frequencies $\left(f>>f_{B}\right.$ ), the transfer function magnitude approaches unity. Thus, this filter passes high frequency components and tends to reject low frequency components.

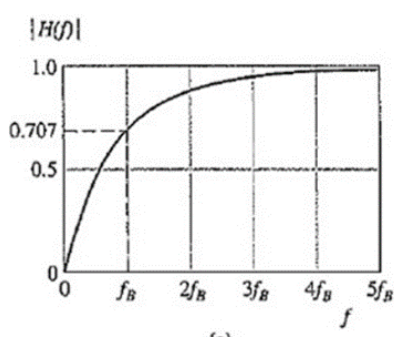

(a)

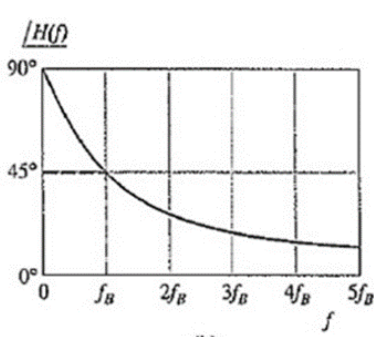

(b)

Fig. 6. Magnitude and phase for the first-order High Pass transfer function [19] 
High pass filter - the preparation phase: Students get the following detailed instructions on how to make the frequency and time domain analysis:

Part 1: Frequency domain analysis (Bode plots):

- Draw a circuit diagram of a simple High Pass $\mathrm{RC}$ filter with $\mathrm{C}=0.1 \mu \mathrm{F}$ and $\mathrm{R}=$ $10 \mathrm{k} \Omega$. Use a voltage source of $1 \mathrm{Vpp}$ (1Volt peak to peak) as an input excitation to the circuit. Identify the output signal.

- Write the transfer function of the filter.

- The size of the transfer function is presented in the theoretical introduction.

- Sketch the Bode plots of the filter, both magnitude and phase. Determine the corner frequency fc of the filter.

- Use OrCAD or MATLAB to simulate the RC filter in frequency domain in order to obtain magnitude and phase response plots.

- Determine the corner frequency from the simulation plots and compare it with the calculated value.

Part 2: Time domain analysis (transients):

- For the circuit shown in Figure 4, switch $\mathrm{S}$ closes at $\mathrm{t}=0 \mathrm{~s}$. Sketch the variation of the capacitor voltage and the current versus time. Assume the capacitor was initially discharged. Calculate the time constant of the transient. Write the analytical expression for the capacitor voltage and the current.

- Use OrCAD or MATLAB to obtain the transient response plots of the capacitor voltage and current as functions of time.

- From the plots determine the time constant of the transients and compare it with the calculated value.

- What is the relationship between the time constant of the circuit and the corner frequency in $\mathrm{rad} / \mathrm{sec}$ ?

High pass filter - the experimental procedures: Students get the following detailed instructions how to use NetLab:

Circuit building:

- Use Circuit Builder to wire and configure the High Pass RC filter analysed in the preparation section. Wire the digital storage oscilloscope (CRO) to observe input voltage at CRO channel 1 and the output signal at CRO channel 2.

- Switch on the function generator and the digital storage oscilloscope. Check the signal displayed on the NetLab oscilloscope screen using the live Internet camerato verify that the images are the same.

Obtaining the frequency response:

- Set the magnitude of the sinusoidal supply voltage to $1 \mathrm{Vpp}$ (1Volt peak to peak) on the signal generator. Check it using oscilloscope.

- Vary the frequency of the supply voltage over the range $(10 \mathrm{~Hz}, 10 \mathrm{kHz})$ to obtain frequency response. Select frequencies: $10 \mathrm{~Hz}, 100 \mathrm{~Hz}, 130 \mathrm{~Hz}, 150 \mathrm{~Hz}, 160 \mathrm{~Hz}$, $170 \mathrm{~Hz}, 180 \mathrm{~Hz}, 200 \mathrm{~Hz}, 500 \mathrm{~Hz}, 1 \mathrm{kHz}, 10 \mathrm{kHz}$ and for each frequency measure the 
magnitudes of the input and output signals (channel 1 and 2), and the phase angle between them.

- Tabulate the results.

Obtaining the transient response:

- Change the waveform of the supply voltage to square wave on the signal generator.

- Set the frequency of the supply voltage to $100 \mathrm{~Hz}$.

- The supply voltage is displayed on channel 1 of the digital storage oscilloscope and the output signal is displayed on channel 2. Change the time scale and magnitude scale for both channels so you can clearly see both signals.

Final activities

- Download the data to your computer.

- Log off from NetLab by closing the Web browser.

High pass filter - the results: The students wired the experimental circuit using the Circuit Builder (Figure 7) and measured the responses according to procedures described in the preceding sections.

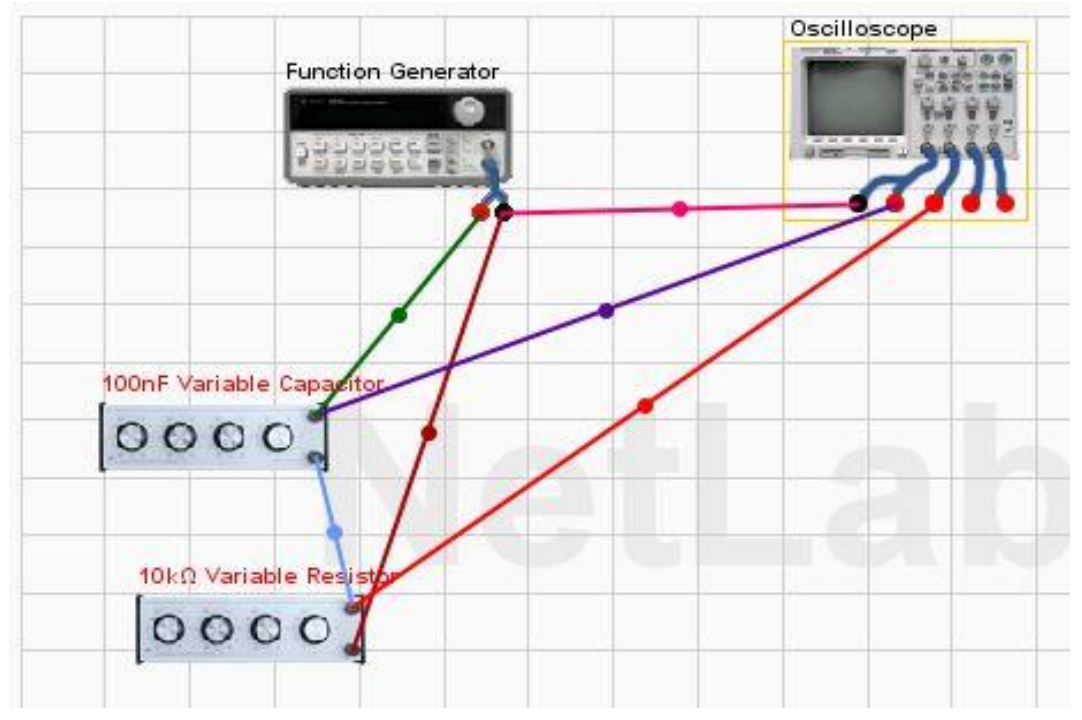

Fig. 7. Circuit Builder for the High Pass Filter experiment

Results from MATLAB/Simulink environment and theoretical calculations are very close to real measurement results using NetLab (Figure 8). Shown here is the phase characteristic of the High Pass Filter, in the frequency range where the greatest differences occurred between calculated, simulated and measured values. 


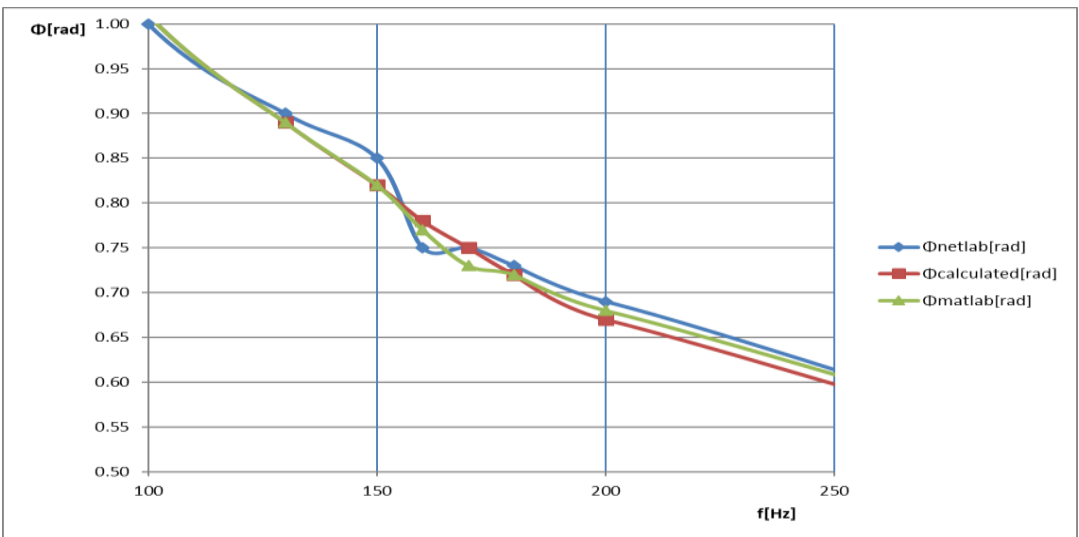

Fig. 8. Comparison of real results using NetLab with theoretical calculations and MATLAB simulations

\section{$5 \quad$ Lublin Student Surveys}

In 2020 in the online offering of the course Monographic Lecture on Remote Laboratories for Master of IT students we have conducted 3 student evaluations: pre-experiment survey, post-experiment survey and the course evaluation. The Polish students used the remote laboratory NetLab, to conduct experiments on resistive-inductive circuits and had to submit laboratory reports in English for the final assessment.

\subsection{Pre-experiment survey}

We have surveyed students from the Lublin University of Technology (LTU) in Poland, of their final (third semester of IT Master degree, full- time enrolment) online studying routines, the use of the Internet in general, and knowledge an proficiency of electronic/electrical circuits in the context of the use of the remote laboratory NetLab, in a pre-experiment survey.

The pre-experiment survey had 4 sections:

1. Basic information about the student

2. Current student study habits and preferences

3. Current level of the student's theoretical knowledge

4. The student's past experience on working with real electronic/electrical circuits and circuit simulators.

Results indicated that some students spent over 60-70 hours per week on the Internet activities that included 20-30 hours for study related. Hand-held devices were used between 10 and 20 hours per week, with minimal use for study purposes.

In the case of study online, half of the respondents were totally online and indicated that if an instructor was present, $71 \%$ of those did not need to ask for assistance at all 
or asked rarely. Self-guided learning or instructor guided learning preferences were split half in half.

In terms of the theoretical knowledge: Ohm's law, series and parallel circuits, knowledge of resistors, capacitors, a multimeter and an oscilloscope, were equally positive as they were building a circuit using those components before.

Responses to 3VRMS voltage setup of a power supply and an unsynchronized oscilloscope were mainly wrong. Responses to a proper voltmeter connection and features were mainly right.

Tools to build circuits indicated predominantly a preference of simulation. This is not surprising in the light of the background of participating students, who had Introduction to Electrical Engineering/Electrical Circuit Theory early in their Bachelor degrees over 5 years ago, and in the current Master of IT the focus was on computer science / software engineering tools.

\subsection{Post-experiment evaluation}

There were 4 sections of the survey:

1. Basic information about the student and their study habits

2. A repeat of the questions from the first survey to test the student's theoretical knowledge

3. Asking students about their experience with and thoughts on remote laboratories

4. Asking students to provide feedback on the intelligent tutoring system.

Only $7.9 \%$ students studied online before the coronavirus. If they had a choice now $86 \%$ of them would choose studying online. The student knowledge regarding electrical/electronic circuits improved as a result of using NetLab and attending the lecture online. They better understand real components and instruments ( $71 \%$ yes). They liked several things in NetLab, including access to real equipment, the camera used to show real instruments responding to their commands, and that they did not need to visit real laboratories and move from home for study.

When asked that can be improved, responses were that the NetLab web browser application was slow but the desktop application was OK and that time lag (jitter) in communication was sometimes unpleasant.

43\% of the students used the Intelligent Tutoring System of Netlab and of those 64\% of them stated it helped them to alert to the circuit problems in the experiments.

\subsection{Course evaluation}

Some of the responses are highlighted. Teaching online is comparable with face-toface in terms of learning outcomes: 57\% agree and strongly agree, neutral 38\% (either is $\mathrm{OK}$ ) on the Likert scale.

Some student comments: $100 \%$ of laboratories can be online, do not need to wake up early, do not need to travel and can save money, can study while at work, recording Skype session helps to come back to the concepts. Good enough. 
Students in the course Diploma Seminar of the same IT Master course cohort responded similarly to the teaching online compared with face-to-face teaching with $55.5 \%$ saying it is comparable, $22.2 \%$ neutral. As a result of the subject $67 \%$ students improved their presentation skills and $77.8 \%$ improved understanding of fellow students' final year projects.

Other comments: learned new ways of presentation, contact with the lecturer very good, learned a lot during the course. This course was very good and there is nothing to improve. Improvements: one platform for all subjects in the university, but Skype is good enough.

\section{Conclusion}

In 2004 a survey was performed to investigate the students' perceptions of their work in NetLab and compare it with their work in a real laboratory. The majority (76\%) of students preferred working in the real laboratory. In 2015 a similar survey was performed - the results were more in favour of remote laboratories, with $50 \%$ of students stated that they had no preference between working in real laboratory or using the remote laboratory NetLab.

The 2017 survey of PhD students of the Lublin University of Technology indicated that $72 \%$ of them agree, strongly agree or are neutral on the Likert scale with the notion that teaching online is comparable with teaching face-to-face. This is a remarkable result, shifting the paradigm of online teaching, including remote laboratories. They are increasingly used in engineering and technology education, in some cases, like in [12], the whole degrees are offered entirely online, including laboratory work.

In 2020 evaluation $57 \%$ of Lublin students agreed and strongly agreed that online learning outcomes are comparable with face-to-face teaching, with neutral $38 \%$ (no preference) on the Likert scale. So, in total $95 \%$ indicated that online teaching is a preferred delivery or have no preference which method of delivery is offered. This is another convincing advance of the online learning preference shift.

Positive e-learning outcomes are reflected in the assessment results where HD (high distinction $-85-100 \%$ ) and $\mathrm{D}$ (distinction $-75-84 \%$ ) were predominantly awarded in the Lublin classes over the years.

Collaborative learning with its potential multicultural dimension is much valued by students and is a very attractive option of remote laboratories that offer it. The skills acquired in the environment of a collaborative remote laboratory are invaluable, especially in the context of the era of globalisation.

Health hazards, such as the recent coronavirus outbreak add additional weight to the value of online remote education, including laboratories [20].

\section{$7 \quad$ References}

[1] Joyce, A. (2019). The power of online learning. University of South Australia, Adelaide, Australia Retrieved on 24 October 2019 from https://www.unisa.edu.au/Enterprise-Magazine-Home/Issue-1-2017/THE-POWER-OF-ONLINE-LEARNING/ 
[2] McIntire, S. and Mirriahi, N. (2019). Learning to teach online. Retrieved on 24 October 2019 from https://www.coursera.org/learn/teach-online

[3] Coursera (2019). Retrieved on 25 October 2019 from https://about.coursera.org/

[4] Nickerson, V., Corter, J.E., Esche, S.K. and Chassapis, C. (2007). A model for evaluating the effectiveness of remote engineering laboratories and simulations in education. Computers \& Education, 49(3): 708-725 https://doi.org/10.1016/j.compedu.2005.11.019

[5] Sicker, D.C., Lookabaugh, T., Santos, J. and Barnes, F. (2005). Assessing the effectiveness of remote networking laboratories. Proceedings of Frontiers in Education 35th Annual Conference, Indianopolis, IN, USA, 6 pp. https://doi.org/10.1109/fie.2005.1612279

[6] Ma, J. and Nickerson, J.V. (2006). Hands-on, simulated, and remote laboratories: A comparative literature review. ACM Computing Surveys, 38(3): 1-24 https://doi.org/10.1145/ 1132960.1132961

[7] Mejías, B.A. and Andújar Márquez, J.M. (2012). A pilot study of the effectiveness of augmented reality to enhance the use of remote labs in electrical engineering education. Journal of Science Education and Technology, 21: 540-557 https://doi.org/10.1007/s10956-0119345-9

[8] Sáenz, J., de la Torre, L., Chacón, J. and Dormido, S. (2019). A new architecture for the design of virtual/remote labs: The coupled drives system as a case of study. Proceedings of 2019 24th IEEE International Conference on Emerging Technologies and Factory Automation (ETFA), Zaragoza, Spain, pp. 769-775 https://doi.org/10.1109/etfa.2019.8869192

[9] Sáenz, J., Esquembre, F., Garcia, F.J., de la Torre, L. and Dormido, D. (2016). A new model for a remote connection with hardware devices using Javascript. Proceedings of 2016 13th International Conference on Remote Engineering and Virtual Instrumentation (REV), Madrid, Spain, pp. 143-144 https://doi.org/10.1109/rev.2016.7444454

[10] Rodriguez-Gil, L., Garcia-Zubia, J., Orduna, P. and Lopez-de-Ipina, D. (2017). Towards new multiplatform hybrid online laboratory models. IEEE Transactions on Learning Technologies, 10(3): 318-330 https://doi.org/10.1109/tlt.2016.2591953

[11] Salzmann, Ch. and Gillet, D. (2011). Remote labs and social media: Agile aggregation and exploitation in higher engineering education. Proceedings of 2011 IEEE Global Engineering Education Conference (EDUCON), Amman, Jordan, 307-311 https://doi.org/10.1109/ educon.2011.5773153

[12] Rohn, J. (2019). Remote laboratory applications. Engineering Institute of Technology, Perth, Australia. Retrieved on 25 October 2019 from https://www.eit.edu.au/cms/resources/practical-online-learning-ebook/chapter-10-remote-laboratory-applications

[13] Garcia-Zubia, J., Cuadros, J., Romero, S., et al. (2017). Empirical analysis of the use of the VISIR remote lab in teaching analog electronics. IEEE Transactions on Education, 62(2): 149-156 https://doi.org/10.1109/te.2016.2608790

[14] Considine, H., Nafalski, A. and Nedić, Z. (2017). Remote laboratory environments for elearning. In: Smart Innovation, Systems and Technologies, Smart Education and E-learning KES-SEEL (eds. V. Uskov, R. J. Howlett and L. C. Jain), Springer International Publishing, 75: 82-91 https://doi.org/10.1007/978-3-319-59451-4 9

[15] Considine, H., Nafalski, A. and Nedić, Z. (2018). Understanding common student mistakes in the remote laboratory NetLab. Proceedings of IEEE International Conference on Teaching, Assessment, and Learning for Engineering (TALE), Wollongong, Australia, pp. 266271 https://doi.org/10.1109/tale.2018.8615348

[16] Nedic, Z., Nafalski, A., Machotka, J. and Göl, Ö. (2011). Enriching student learning experiences through international collaboration in remote laboratories. NSW, Australia, $41 \mathrm{pp}$.

[17] Nedic, Z., Machotka, J. and Nafalski, A. (2011). Enriching student learning experiences in remote laboratories. Proceedings of the 2nd World Institute for Engineering and Technology 
Education WIETE Annual Conference on Engineering and Technology Education, Pattaya, Thailand, pp. 9-14

[18] Teng, M., Considine, H., Nedic, Z., Nafalski, A. (2016). Current and future developments in remote laboratory NetLab. International Journal of Online Engineering (iJOE), 12(8), pp. 4-12

[19] Robbins. A.H. and Miller, W.C. (2007). Circuit analysis: Theory and practice, DELMAR

[20] Ziguras, C. and Tran, L. (2020). Coronavirus outbreak is the biggest crisis ever to hit international education. Retrieved on 13 February 2020 from http://theconversation.com/thecoronavirus-outbreak-is-the-biggest-crisis-ever-to-hit-international-education-131138

\section{Authors}

Andrew Nafalski, PhD, DSc is currently an Adjunct Professor of the University of South Australia, an Honorary Professor and Visiting Professor at the Lublin University of Technology, Poland. He has had some fifty years of his academic career in Poland, Austria, Japan, Germany, Wales, USA, Canada, France, Australia, et al.

Marek Miłosz, PhD (Eng) is a Professor of the Lublin University of Technology, Poland. He has had several tens of years of academic experience in Poland, France, Spain, Finland, Slovenia, Lithuania, Hungary, Russian Federation, Kazakhstan, Kyrgyzstan and Uzbekistan. m.milosz@pollub.pl

Hugh Considine has BSoftwareEng (Honours) and BEng (Computer Systems Engineering) degrees from the University of South Australia, where he is currently employed and finalises his PhD on 'Intelligent tutoring system for remote laboratories with the application of learning analytics’. hugh.considine@unisa.edu.au

This article is a revised and extended version of a paper presented at the EDUCON2020 conference held in Porto, Portugal, in April 2020. Article submitted 2020-06-25. Resubmitted 2020-07-09. Final acceptance 2020-07-09. Final version published as submitted by the authors. 